\title{
Formation of sucrose crystallization centers and their growth in a vacuum apparatus
}

\author{
Anatoliy Slavyanskiy, ${ }^{1,}$, Natalia Lebedeva ${ }^{1}$, and Vladimir Voitsekhovsky ${ }^{2}$ \\ ${ }^{1}$ K.G. Razumovsky Moscow State University of technologies and management (the First Cossack University), 109004 Moscow \\ Zemlyanoy Val str. 73, Russia \\ ${ }^{2}$ National University of Life and Environmental Sciences of Ukraine, 03041 Kyiv Heroiv Oborony Str.15, Ukraine
}

\begin{abstract}
The article considers sucrose crystallization as a mass transfer process, which is a phase transition from a liquid phase to a solid phase, and includes two main stages: the formation of crystallization centers and the growth of crystals to the desired size. The scientific novelty of the work lies in the development of existing theoretical and practical ideas about the formation of centers of crystallization of sucrose and their growth in the massecuite mass, the analysis of the main factors affecting this process. On the basis of the studies obtained, a method has been developed to improve the efficiency of the technology for boiling the massecuite of the first crystallization, which refers to the methods of boiling the massecuite I crystallization with intermediate centrifugation of the massecuite. A feature of the method is the formation of crystallization centers in the massecuite by their spontaneous formation. The analysis of the obtained research results showed that the work on the proposed method makes it possible to increase the efficiency of boiling massecuite I crystallization, to ensure an increase in the yield and quality of crystalline white sugar.
\end{abstract}

\section{Introduction}

Crystallization of sucrose is a mass transfer process, which is a phase transition from a solution (liquid phase) to a crystallisate (solid phase). In this case, impurities (socalled non-sugar) are removed from the initial sucrose solution using a purification process.

It is known that with a single crystallization process, it is possible to obtain white sugar with a purity of $99.8 \%$, but it is impossible to completely purify sucrose from impurities [1].

The crystallization process of sucrose is accompanied by the following reactions:
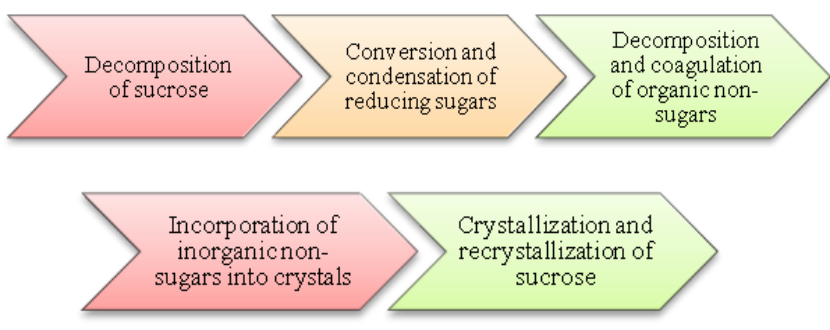

The intensity of these processes largely depends on the technological conditions of the crystallization of sucrose in vacuum apparatus, and the purity of white sugar largely depends on the conditions of the crystallization process and the qualitative composition of the initial products [2].

The crystallization process of sucrose consists of two main stages:

1. the formation of crystallization centers;

2. growing crystals to the required size.
Moreover, the first stage largely determines the nature and characteristics of the second stage of this process [3].

The formation of centers of crystallization of sucrose is understood as a multi-stage process of gradual increase in its pre-embryonic complexes that do not have a crystal lattice to the formation of associates. Then, as the saturation increases during the evaporation of water from the sucrose solution and the intensity of their formation increases, the associates transform into quasicrystals, which, having reached a certain size, subsequently serve as centers of sucrose crystallization.

Crystallization centers can be formed in supersaturated sugar solutions in both homogeneous and heterogeneous ways. A homogeneous process of the formation of crystallization centers is possible in sufficiently pure sugar solutions, and under industrial conditions there is a heterogeneous mechanism for the formation of crystals [4].

The formation of a new phase is possible only when a supersaturated sugar solution passes from a metastable state to a labile (unstable) one. This is due to the fact that the nucleation of crystals is possible only with incomplete hydration of sucrose molecules, which is characteristic of labile solutions.

For the first time, the conditions for the formation of a new phase from the point of view of thermodynamics were formulated by D. Gibbs, and then they formed the basis of M. Volmer's theory, explaining the formation of a new phase under stationary conditions.

However, in contrast to these concepts, the nucleation of crystallization centers occurs in time, i.e. in

\footnotetext{
* Corresponding author: slavyanskiyaa@mgutm.ru
} 
nonstationary conditions, which was taken into account in the works of other researchers [5].

The thermodynamic theory of the formation of a new phase reveals the mechanism of crystal formation only from the point of view of layered growth. In addition, the molecular kinetic theory developed by I.N. Stransky and R.K. Kaishev, as well as the theory of E.V. Hamsky, based on the ideas of chemical kinetics.

According to the molecular kinetic theory of I.N. Stransky and K.R. Kaishev, the process of formation of a nucleus of a critical size occurs gradually due to the attachment of building elements to growing crystals.

According to the theory of E.V. Hamsky, both in a supersaturated and in a saturated solution, there may be embryos. Moreover, the transition from a pre-embryo to an embryo can occur by attaching one or several simple particles to it [6].

Under production conditions, crystallization centers are created artificially, for which the sugar solution is thickened to a supersaturation coefficient of 1.25-1.3 (labile state) and a seed material is introduced into it, which is an impulse for the emergence of new crystallization centers in the entire volume of the solution [7].

Most often, powdered sugar or special pastes (seed suspensions) are used to form crystals when cooking massecuite. Seed crystals are obtained in two ways: grinding and crystallization. The seed material obtained by grinding has a number of disadvantages: the inability to control the process, the need to use expensive equipment, as well as the duration and complexity of their production. In addition, it is difficult to dose into the vacuum apparatus the amount of seed crystals required for complete filling, since the grinding method does not allow obtaining crystals of a high degree of homogeneity [8].

A known method of using seed suspensions, which are obtained by grinding sugar crystals $0.2-0.7 \mathrm{~mm}$ in size in isopropyl or butyl alcohol while maintaining their volume ratio 1: (2-2.2) in a ball mill. The resulting suspension should contain in $100 \mathrm{~g}$ at least $150 \times 10^{9}$ crystallization centers of sucrose with a size of 10-25 microns [9].

Another method of obtaining crystals of a seed suspension is based on a decrease in the solubility of sucrose due to the evaporation of the solvent and the subsequent growth of crystals upon cooling. For this, a saturated sugar-containing solution is prepared at 105$108^{\circ} \mathrm{C}$, which is then divided into two parts in a ratio of $1: 2-1: 3$. A smaller part is cooled in vacuum to $45-50^{\circ} \mathrm{C}$ to obtain $40-50 \%$ of crystals, then it is mixed with the greater part, as a result of which the temperature of the mixture is set equal to $85-90^{\circ} \mathrm{C}$. Crystals increase, reducing the temperature of the mixture to $75-80^{\circ} \mathrm{C}$, while the content of crystals in the suspension reaches $25-30 \%$. The disadvantages of this method include the difficulty of preparing and heating the sugar-containing solution above $100^{\circ} \mathrm{C}$, which increases the loss of sucrose due to thermal decomposition [10].

According to other authors, good results are obtained when using the three-component seeding paste "Magmas". This is a finished product that does not require special preparation before loading into a vacuum apparatus. This type of paste, in addition to fine sugar and ethyl alcohol, contains a surfactant that improves the conditions for crystal formation and reduces the viscosity of the product in a vacuum apparatus [1].

Sapronov A.R. believes that the use of special suspensions with a particle size of 10-25 microns as a seed material improves the control of the amount of crystals in the massecuite, and also allows you to obtain crystalline sugar with a good granulometric composition [3].

Christian Moller notes in his study that even when crystals are sealed with a special seed paste, single crystals reaching 50 microns during growth are at high risk of merging with other similar crystals and continue to grow together as one intergrown crystal. In this case, after the crystals reach $150 \mu \mathrm{m}$ in size, the probability of the formation of double crystals tends to a minimum [4].

In recent years, sugar mills have often used the Braunsheig method to create crystallization centers, in which the process of initial formation and fixation of sucrose crystals is separated from the main operations of massecuite cooking. Accordingly, by the microsaturation method, sucrose is mixed with glycerin, thickened to 76$78 \% \mathrm{DM}$, seed crystals are first grown when cooled to a size of 0.1-0.12 mm, and then by evaporation of water, they are increased to $0.3 \mathrm{~mm}$. Further on this mother liquor massecuite is cooked in industrial vacuum apparatus [8].

According to the research of L.A. Sapronova, in contrast to the Braunschweig method, its technology eliminates the adhesion of microcrystals and their subsequent agglomeration. In addition, it is not necessary to prepare master massecuite with crystals of about 0.3 $\mathrm{mm}$ from the seed suspension in a separate intermediate apparatus [3].

According to some other researchers, to eliminate the disadvantages of using powdered sugar and seed paste for boiling the massecuite of the first crystallization, you can use the original uterine massecuite.

The preparation of master massecuite consists in creating crystallization centers and their subsequent fixation in a special cooling crystallizer under certain conditions, increasing them with supersaturation 1.051.10 to $100-120$ microns, and then increasing them in a separate vacuum apparatus during boiling to 200-350 microns. It is believed that the use of the original master massecuite can improve the granulometric composition of crystalline white sugar, thereby increasing its yield and reducing water consumption for washing crystals in the field of centrifugal forces [11].

It is possible to increase the homogeneity of sugar crystals and reduce the number of intergrowths in their composition by boiling the massecuite in a vacuum apparatus with a mechanical stirring device.

An increase in the circulation of the massecuite in the vacuum apparatus is also possible due to the use of the secondary vapor of the evaporator when cooking the massecuite. The optimum flow rate of injected steam is 4$6 \%$ of the steam flow rate for heating the steam chamber of the vacuum apparatus. It was found that with an increase in the concentration of the sugar solution, the efficiency of steam injection increases.

The conditions for the formation of crystallization centers strongly affect the granulometric composition of 
crystalline sugar, therefore, when obtaining massecuite of the first crystallization, it is necessary to pay special attention to the stage of nucleation of crystals in it [1, 3].

With spontaneous filling of crystallization centers, crystals begin to grow from the moment their nuclei reach a certain size. If a seed material is used for these purposes, then the process of their growth begins from the moment it is introduced into a saturated solution [12].

\section{Materials and methods}

The purpose of these studies is a quantitative analysis of the phenomenon of spontaneous crystallization of sucrose during thickening of the massecuite of the first crystallization in a vacuum apparatus in the period of time preceding the filling of crystallization centers in the thickened syrup. In other words, the spontaneous initiation of sugar crystals in saturated syrup in the metastable zone during boiling of the massecuite of the first crystallization is investigated in terms of the growth of sugar crystals and the time of their formation.

It is assumed that the initial dispersed system is monodisperse, as in a pure solution, which includes only sucrose molecules. In this case, the rate of coagulation is determined by the intensity of the Brownian motion of particles, characterized by the number of collisions per unit time, the initial concentration of particles, and the presence of only an attractive force between the particles [12].

Choosing as the initial kinetic relation in the form of the equation of nonstationary coagulation

$\partial n / \partial t=0,5 \int_{0}^{\infty} \int_{0}^{\infty} \gamma\left(m^{\prime}, m^{\prime \prime}\right) D\left(m, m^{\prime}, m^{\prime \prime}\right) n\left(m^{\prime}\right) n\left(m^{\prime \prime}\right) d m^{\prime} d m^{\prime \prime}$, as well as the initial condition $n(m, t)=n_{0}(m)$ at $\mathrm{t}=0$, crystallization of sucrose in a batch vacuum apparatus was investigated as a spontaneous coagulation process. Moreover, as the core of coagulation, we chose $\beta\left(m^{\prime}, m^{\prime \prime}\right)=b \gamma\left(m^{\prime}, m^{\prime \prime}\right)$, where $b=2 k_{\mathrm{b}} \theta /\left(3 \mu_{ж}\right)$; $\gamma\left(m^{\prime}, m^{\prime \prime}\right)=\left(m^{\prime 1 / 3}+m^{\prime 1 / 3}\right)\left(1 / m^{\prime 1 / 3}+1 / m^{\prime \prime 1 / 3}\right)=$ $=\left[2+\left(m^{\prime} / m^{\prime \prime}\right)^{1 / 3}+\left(m^{\prime \prime} / m^{\prime}\right)^{1 / 3}\right]$.

Assuming that the initial volume of the solution includes only sucrose molecules with a mass of $m_{1}=$ $5.7 \times 10^{-24} \mathrm{~kg}$, the calculated particle distribution density in the initial liquid mixture is taken as $n_{0}(m)=N_{0} \delta\left(m-m_{1}\right)$.

Based on a number of mathematical transformations, the crystallization period of sucrose can be determined using the equation [12]

$$
T=\frac{3 \mu_{\mathscr{F}}}{\mathbf{4} \bar{\gamma} k_{\bar{b}} \theta N_{\mathbf{0}}} \text {. }
$$

The results from the calculations carried out on the spontaneous coagulation process are presented in the form of data in Table 1.

Table 1. Values of distribution functions depending on the mass of the crystal during thermal fluctuation coagulation for different periods of crystallization

\begin{tabular}{|c|c|c|c|c|c|c|}
\hline $\begin{array}{c}m, m_{1}= \\
8,2 \times 10^{-24} \\
\mathrm{~kg}\end{array}$ & $m_{1}$ & $2 m_{1}$ & $3 m_{1}$ & $4 m_{1}$ & $5 m_{1}$ & $10 m_{1}$ \\
\hline
\end{tabular}

\begin{tabular}{|c|c|c|c|c|c|c|}
\hline$\delta \times 10^{9} \mathrm{~m}$ & 1,0 & 1,26 & 1,44 & 1,59 & 1,71 & 2,15 \\
\hline $\begin{array}{c}F(m), \%, \\
\mathrm{~T}= \\
1,35 \times 10^{-} \\
8 s\end{array}$ & 53,33 & 71,11 & 77,04 & 79,01 & 79,67 & 80 \\
\hline $\begin{array}{c}F(m, \mathrm{i}+1) \\
-F(m, \mathrm{i})\end{array}$ & - & 17,78 & 5,93 & 1,97 & 0,66 & 0,33 \\
\hline $\begin{array}{c}F(m), \%, \\
\mathrm{~T}= \\
2,7 \times 10^{-8} s\end{array}$ & 44,44 & 64,20 & 65,84 & 66,39 & 66,58 & 66,67 \\
\hline $\begin{array}{c}F(m, \mathrm{i}+1)- \\
F(m, \mathrm{i})\end{array}$ & - & 19,76 & 1,64 & 0,55 & 0,19 & 0,09 \\
\hline
\end{tabular}

Note: $m$ - is the mass of a sucrose molecule, $\mathrm{kg} ; \delta$ - is the size of the sucrose molecule, $\mathrm{m} ; F-$ is the value of the distribution function at time $\mathrm{T}, \%$.

From the data in Table 1, it follows that the distribution function $F(m)$ has a stepwise increasing character, reflecting the dynamics of crystal formation over the calculated periods of the process. For example, over the time period $\mathrm{T}=1.35 \times 10^{-8} \mathrm{~s}$, the relative content of monomers (molecules) in the solution decreases to $53.33 \%$. In addition, due to the combination of molecules in solution, doublets appear, the relative content of which is $71.11-53.33=17.78 \%$, triplets $-77.04-71.77=5.93 \%$, the relative number of aggregates with the number molecules of more than five $-80-79.67=0.33 \%$ (fourth row of Table 1), etc.

Comparison of the data in the columns of the table indicates a decrease over time in the relative content of both monomers and aggregates of each particle multiplicity (third and fifth rows of Table 1). Moreover, if with an increase in the time of the process, the specific number of doublets from sucrose particles increases, then the relative content of larger ones decreases. In other words, in general, due to a decrease in the countable concentration of sucrose particles, there is a decay in time of the process and crystal formation.

\section{Results}

Based on the simulation of this process in a production environment, a new method for obtaining massecuite of the first crystallization was developed, the implementation scheme of which is shown in Figure 1 [13].

The developed method relates to methods for boiling massecuite I crystallization with intermediate massecuite centrifugation. A feature of the method is the formation of crystallization centers in the massecuite by their spontaneous formation. In this case, the number of formed embryos is $8-12$ pcs. per $1 \mathrm{~mm}$ of the length of the surface of the test glass. For this, the degree of supersaturation of the syrup is brought to $1.3-1.4$ at a temperature of 78$82^{\circ} \mathrm{C}$ and then the solution is rapidly cooled until crystallization centers appear. For this purpose, the supply of heating steam to the steam chamber of the vacuum apparatus is regulated. After that, sugar crystals are built up to their content in the massecuite in the range of 40 $42 \%$ by weight. 


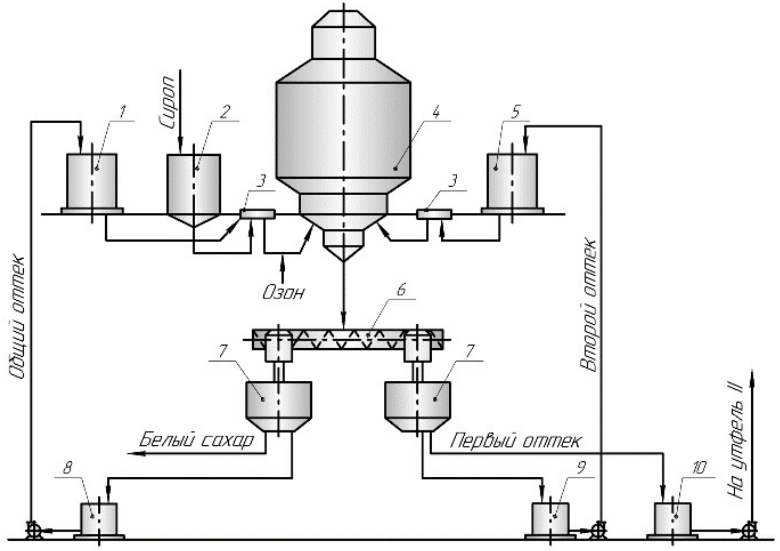

Fig. 1. Technological scheme for obtaining massecuite of the first crystallization according to the patent of the RU 2472860: 1 - collection of general sludge; 2 - collection of syrup; 3 collector; 4 - vacuum apparatus; 5 - collection of the second flow; 6 - utterance mixer; 7 - centrifuge; 8 - collection of general flow; 9 - collection of the second effluent after centrifuges; 10 - collection of the first sludge after centrifuges

The developed method relates to methods for boiling massecuite I crystallization with intermediate massecuite centrifugation. A feature of the method is the formation of crystallization centers in the massecuite by their spontaneous formation. In this case, the number of formed embryos is $8-12$ pcs. per $1 \mathrm{~mm}$ of the length of the surface of the test glass. For this, the degree of supersaturation of the syrup is brought to $1.3-1.4$ at a temperature of $78-$ $82^{\circ} \mathrm{C}$ and then the solution is rapidly cooled until crystallization centers appear. For this purpose, the supply of heating steam to the steam chamber of the vacuum apparatus is regulated. After that, sugar crystals are built up to their content in the massecuite in the range of 40 $42 \%$ by weight.

The selection of part of the massecuite from the vacuum apparatus is carried out in the amount of $35-40 \%$ of the total mass. The massecuite remaining in the vacuum apparatus is boiled down on pumping syrup until it contains $88-89 \%$ of dry matter. Then ozonation is carried out. In this case, the return of the outflow of the selected part of the massecuite is carried out after feeding the syrup.

During the test period, massecuite I crystallization was boiled from syrup with a purity of $92.2-92.4 \%$ in a vacuum apparatus. At the very beginning of the process, the syrup was taken into a vacuum apparatus above the level of the steam chamber and concentrated to a supersaturation coefficient of 1.30-1.37. The planting of crystallization centers was carried out by their spontaneous formation at a rate of 10-12 pcs. crystal nuclei per $1 \mathrm{~mm}$ of the length of the surface of the test glass, which was achieved by adjusting the supply of heating steam into the steam chamber of the apparatus. The growth of crystals was carried out on systematic pumping of syrup, preheated by $5^{\circ} \mathrm{C}$ above the boiling point of the massecuite $\left(75^{\circ} \mathrm{C}\right)$. When the massecuite reached $40-42 \%$ of the crystals by weight, a part of this massecuite in the amount of $35-40 \%$ of the total mass was taken from the vacuum apparatus and sent to centrifugation, where it was separated into crystalline sugar and two effluents.

The massecuite remaining in the vacuum apparatus was rocked with syrup with simultaneous ozonation for 5 min, for which ozone was introduced into the massecuite in an amount of 6-7.5 g/ $\mathrm{m}^{3}$. Then, the crystals were regrown in the syrup, and the second outflow of the selected part of the massecuite was fed into the vacuum apparatus for the last pumping. After that the massecuite was brought to readiness, thickening it to $92.2-92.5 \%$ of dry matter $[4,13]$.

In parallel, the massecuite I of crystallization was boiled according to the already known method.

The results of boiling massecuite I crystallization are shown in Table 2.

Table 2. Average results of boiling massecuite I crystallization

\begin{tabular}{|c|c|c|}
\hline \multirow[b]{2}{*}{ Main factors } & \multicolumn{2}{|c|}{ Boiling technology } \\
\hline & $\begin{array}{c}\text { The } \\
\text { famous }\end{array}$ & $\begin{array}{l}\text { The } \\
\text { propose } \\
\text { d }\end{array}$ \\
\hline $\begin{array}{l}\text { Purity of massecuite I } \\
\text { crystallization, } \%\end{array}$ & 92.5 & 92.5 \\
\hline $\begin{array}{l}\text { Dry matter content of massecuite I } \\
\text { crystallization, } \%\end{array}$ & 92.5 & 92.5 \\
\hline Massecuite boiling time, $\mathrm{h}$ & 3.2 & 2.8 \\
\hline \multicolumn{3}{|c|}{ Physical and chemical quality indicators: } \\
\hline Color, conventional units & 0.8 & 0.7 \\
\hline Turbidity, physical units & 26.0 & 22.2 \\
\hline Reducing substances, $\%$ & 0.05 & 0.04 \\
\hline Cinder, \% & 0.030 & 0.026 \\
\hline \multicolumn{3}{|l|}{ Grading: } \\
\hline Average crystal size, mm & 0.56 & 0.72 \\
\hline Coefficient of heterogeneity, $\%$ & 35.0 & 28.0 \\
\hline
\end{tabular}

\section{Conclusion}

The analysis of the results obtained showed that the work on the proposed method allows to reduce the time of massecuite boiling by an average of 0.5 hours. The granulometric characteristics of the sugar are improved. In this case, the sugar produced has an average crystal size of $0.72 \mathrm{~mm}$, and the coefficient of heterogeneity is $28 \%$.

In addition to improving the physicochemical parameters of sugar, the improved technology compared with the known method allows you to increase the yield of crystalline white sugar by $0.05 \%$ by weight of beets.

\section{References}

1. A.A. Slavyansky, Special technology of sugar production (Publishing house "Lan", St. Petersburg, 2020)

2. J. Grbic, R. Jeutic, Sugar Industry 13311 699-703 (2008)

3. A.R. Sapronov, L.A. Sapronova, S.V. Ermolaev, Sugar technology (Publishing House "Profession", St. Petersburg, 2015) 
4. N.N. Lebedeva, Development of an effective technology of boiling up the first crystallization snap (2013)

5. A. Gharsallaoui, B. Roge, Mathlouthi, Food Chemistry 106 1443-1453 (2008)

6. L. San, M. Bento, Sugar Industry 13412 743-746 (2009)

7. E.V. Semenov, A.A. Slavyansky, E.A. Sergeeva, T.A. Shchitova, Sugar 3 46-50 (2013)

8. M. Walter, B. Ekelhof, S. Heppner, D. Wullbrandt, Sugar Industry 13412 747-755 (2009)

9. H. Nurmi, B. Wieded, R. Friberg-Andersen, Sugar Industry 1334 211-218 (2008)

10. P. Eduardo de Morais Gonzales, I. Rossi Fermo, E. Leandro Almeida, C. Marcos, 10th international conference on sustainable energy and environmental protection, mechanical engineering 29-39 (2017)

11. V.I. Tuzhilkin, M.G. Balykhin, S.M. Petrov, N.M. Podgornova, N.D. Lukin, V.A. Kovalyonok, Journal of Food Engineering 306110614 (2021)

12. E.V. Semenov, A.A. Slavyansky, N.N. Lebedeva, Sugar 10 44-49 (2011)

13. A.A. Slavyansky, N.N. Lebedeva, First crystallization shoulder production method Patent RU 2472860 (2013) 